07,12

\title{
Рентгеновские исследования формирования доменов в горных породах под взрывным воздействием
}

\author{
() М.Д. Шарков ${ }^{1}$, М.Е. Бойко ${ }^{1}$, А.М. Бойко ${ }^{1}$, В.А. Боровиков ${ }^{2}$, \\ М.Н. Григорьев ${ }^{3}$, С.Г. Конников ${ }^{1}$ \\ ${ }^{1}$ Физико-технический институт им. А.Ф. Иофрфе РАН, \\ Санкт-Петербург, Россия \\ ${ }^{2}$ Санкт-Петербургский политехнический университет Петра Великого, \\ Санкт-Петербург, Россия \\ ${ }^{3}$ Балтийский государственный технический университет „Военмех“ им. Д.Ф. Устинова, \\ Санкт-Петербург, Россия \\ E-mail: mischar@mail.ru, boikomix@gmail.com
}

(Поступила в Редакцию 14 апреля 2016 г.)

На пластинах кварца, помещенных в бетон, смоделирована процедура взрывной отбойки горных пород. Методом малоуглового рассеяния рентгеновских лучей исследованы образцы-фрагменты кварца, образовавшиеся в результате отбойки. Получены приблизительные размеры зерен от 200 до $220 \mathrm{~nm}$ во фрагментах кварца. Показано, что в образцах присутствуют низкоразмерные (линейчатые) составляющие и что по мере отдаления образца от центра взрыва зерна в нем укрупняются. Оценены параметры сверхрешетки в изученных фрагментах. Сформулирована гипотеза о том, что доменные границы в образцах-фрагментах кварца представляют собой линейчатые объекты — дислокационные стенки.

\section{1. Введение}

Природный алмаз представляет собой кристаллический углерод $\mathrm{C}^{12}$ с небольшим (до 5\%) количеством примесей в виде окиси железа и кремнезема со следами извести и магнезии [1]. Коренное месторождение алмазов, как правило, имеет вид вертикальной воронкообразной трубки, заполненной кимберлитом. Кимберлит является алмазоносной магматической породой, которая состоит главным образом из оливина, бурой слюды и пироксена [2]. Алмазы образуются в кимберлите в результате кристаллизации углерода при высоких температурах и больших давлениях. Кубическая (алмазная) фаза углерода является стабильной при температурах выше $2000 \mathrm{~K}$ и давлениях выше $100 \mathrm{kbar}$ [3].

При добыче минералов, в том числе алмазов, часто применяется метод взрывной отбойки [4], нацеленный на разрушение кристалловмещающей породы. Качество добываемых минералов (как объектов для последующей обработки) в значительной мере связано с присутствием в них визуально не наблюдаемых дефектов кристаллической структуры, так как эти дефекты являются зародышами вероятных разрушений (чаще всего по плоскостям спайности). В данной работе в рамках задачи оценки качества добываемых минералов исследуется воздействие взрыва на кристаллы, добываемые методом взрывной отбойки.

Обычно в горных породах, содержащих высокомодульные кристаллы (т.е. с высокими характеристиками прочности и твердости) и подвергнутых процедуре взрывной отбойки, могут быть выделены три области по критерию воздействия взрывных волн на добываемые кристаллы. Это так называемые зоны разру- шения, трещинообразования и откола [4], в которых доменная структура материала существенно различается. Схематически взорванная горная порода показана на рис. 1.

Алмазное сырье является дорогостоящим материалом (рыночные цены на монокристаллы массой $200 \mathrm{mg}$ могут составлять по порядку величины от 10 USD до ста тысяч USD). Поэтому взрывная отбойка, осуществленная с целью получения образцов для лабораторных исследований, была проведена не на реальной алмазоносной породе, а на модельном объекте. Подбор материалов для моделирования кристаллов алмаза и кимберлитовой породы осуществлялся исходя из критерия сходства модели с оригинальными материалами (кристаллами и породой) по плотности и твердости.



Рис. 1. Схематический вид зон разрушения (1), трещинообразования (2) и откола (3) во взорванном материале. Место исходного расположения заряда заштриховано. 
Твердость минералов по шкале Мооса

\begin{tabular}{c|l}
\hline Твердость по Моосу & \multicolumn{1}{c}{ Минерал } \\
\hline 1.0 & Тальк \\
2.0 & Гипс \\
3.0 & Кальцит \\
4.0 & Флюорит \\
5.0 & Апатит \\
6.0 & Калиевый полевой шпат \\
7.0 & Кварц \\
8.0 & Топаз \\
9.0 & Корунд (сапфир) \\
10.0 & Алмаз
\end{tabular}

В таблице приведена шкала Мооса твердости природных минералов.

В качестве модели был выбран бетонный блок, внутри которого - в процессе его заливания - были размещены несколько монокристаллических пластин синтетического кварца.

В данной работе применена методика малоуглового рассеяния рентгеновских лучей (МУРР) [5], обычно используемая для определения размеров наночастиц в аморфных материалах или порошках. В применении к монокристаллам эта методика позволяет оценить размеры и форму несовершенств в кристаллах, таких, как домены и флуктуации плотности. Метод МУРР полезен при исследовании в образце свойств и характеристик микро- и нанообъектов (доменов, зерен, пор) [6], в том числе объектов, образующихся под воздействием взрывных волн.

\section{2. Эксперимент}

Был произведен взрыв образца-модели горной породы, представлявшего собой блок бетона марки 100 , близкого по механическим свойствам к кимберлиту, в котором были размещены монокристаллические пластины синтетического кварца размера $15 \times 15 \times 0.35 \mathrm{~mm}$ с ориентацией (0001). Использовались три набора пластин, размещенных внутри бетонного блока на расстояниях около 150,300 и $500 \mathrm{~mm}$ от центра взрыва соответственно. Объемы бетона, задействованные при непосредственном заливании кварцевых пластин, а также сами пластины были маркированы краской, выбранной в соответствии с расстоянием от данной (заливаемой) пластины до центра взрыва.

В работе представлены результаты исследования методом МУРР трех образцов, изьятых из взорванного материала на расстоянии 150,300 и $500 \mathrm{~mm}$ и содержащих фрагменты кварцевых пластин. Отбор образцов проводился в соответствии с цветовой маркировкой, чтобы были выбраны образцы, включающие в себя фрагменты кварцевых пластин каждого из трех наборов (соответствующих исходному расстоянию от данного фрагмента

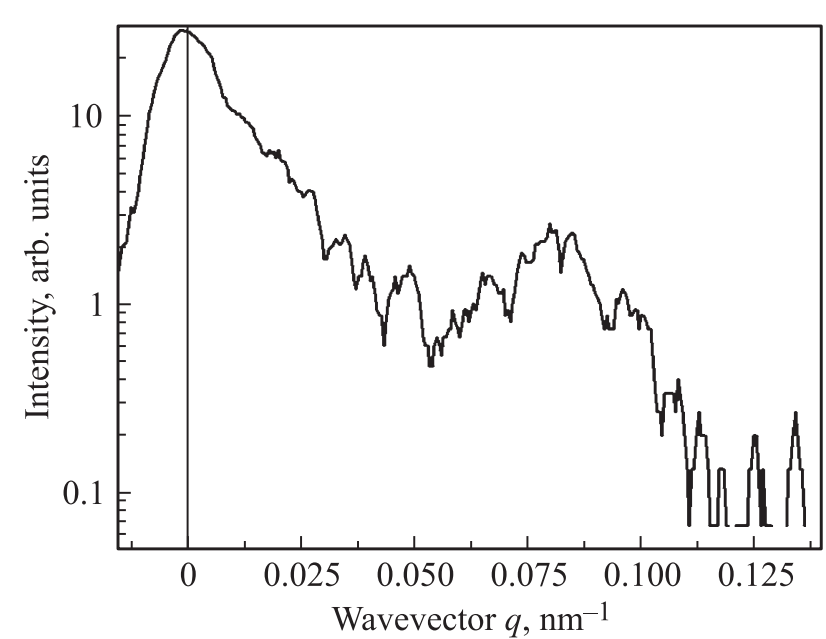

Рис. 2. Кривая МУРР, полученная в просвечивающем режиме на $\mathrm{Cu} K_{\alpha 1}$-излучении от образца-фрагмента кварцевой пластины, изначально расположенной в бетонном блоке на расстоянии $150 \mathrm{~mm}$ от места центра взрыва.

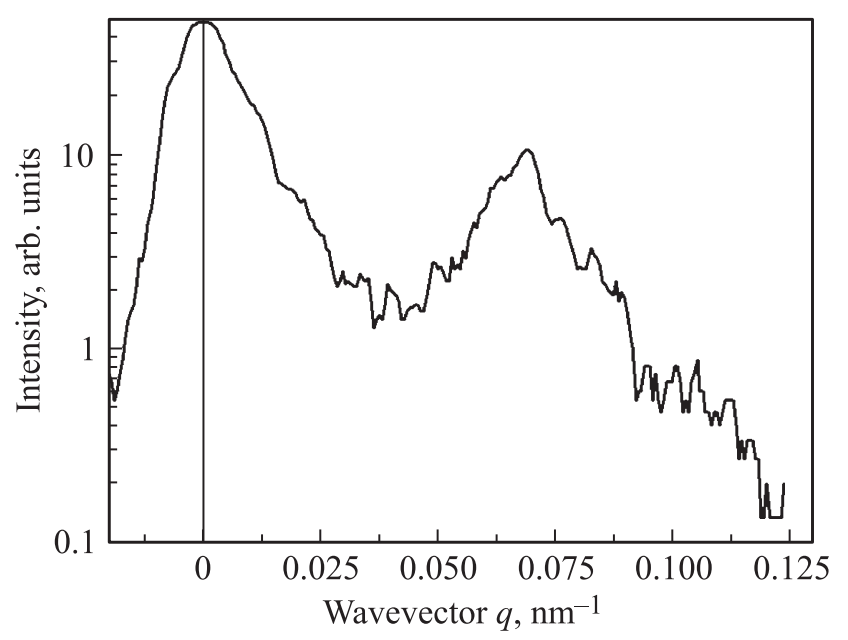

Рис. 3. То же, что на рис. 2 для расстояния $300 \mathrm{~mm}$ от места центра взрыва.

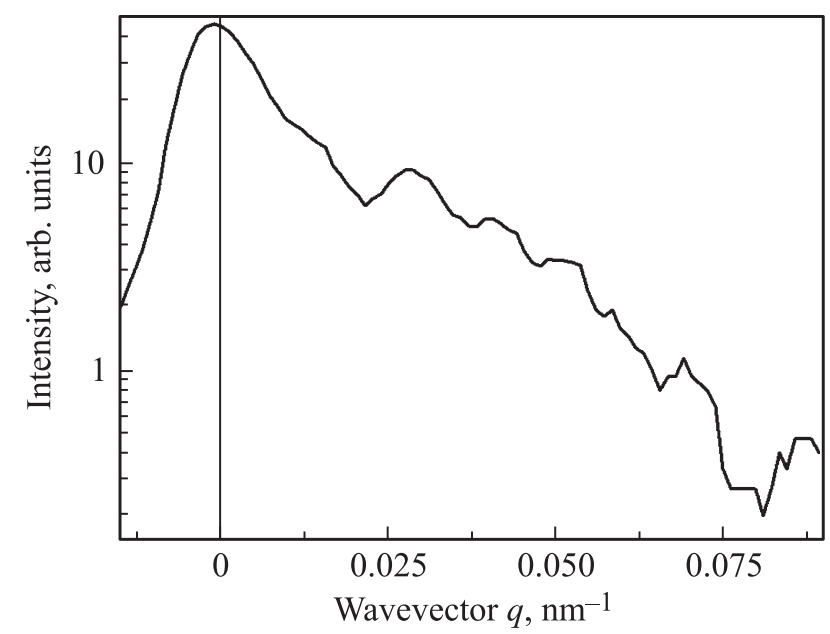

Рис. 4. То же, что на рис. 2 для расстояния $500 \mathrm{~mm}$ от места центра взрыва. 




Рис. 5. Кривая МУРР, полученная в просвечивающем режиме на $\mathrm{Cu} K_{\alpha 1}$-излучении от контрольного образца кварца.

кварцевой пластины до центра взрыва). Кривые дифракционного рассеяния (КДР) МУРР были получены на лабораторной установке МАРС-2 (ФТИ им. А.Ф. Иоффе) в просвечивающем режиме при $\mathrm{Cu} K_{\alpha 1}$-излучении (длина волны $1.5405 \AA$ ). Кривые МУРР, полученные от образцов, находившихся изначально на расстояниях 150, 300 и $500 \mathrm{~mm}$ от центра взрыва соответственно, приведены на рис. $2-4$.

Также была измерена кривая МУРР от контрольного образца - кварцевой пластины, не подвергнутой процедуре моделирования взрывной отбойки. Данная КДР приведена на рис. 5.

\section{3. Анализ данных и результаты}

При численном анализе кривых МУРР, измеренных в просвечивающем режиме, следует иметь в виду следующий момент. Малоугловая КДР может содержать два основных вклада, один из которых обусловлен непосредственным рассеянием пучка на неоднородностях в образце, а второй связан с межчастичной интерференцией. Фрагменты КДР, сформированные преимущественно первым из этих двух вкладов, обрабатываются в соответствии с моделями Гинье и Порода [6,7]. Второй вклад - интерференционный - проявляется главным образом как набор брэгговских (интерференционных) максимумов, характеризующих пространственные периоды в образце, по порядку величины существенно превосходящие межатомные расстояния. Это могут быть, например, толщины слоев или межплоскостные расстояния в сверхрешетках [7].

Анализ полученных кривых МУРР в соответствии с моделью Гинье показал, что размеры однородностей (зерен, доменов) составляют: в образцах, располагавшихся на расстоянии $150 \mathrm{~mm}$ от центра взрыва, около $202 \mathrm{~nm}$; при изначальном расстоянии $300 \mathrm{~mm}$ от центра взрыва - $206 \mathrm{~nm}$; в случае удаленности на $500 \mathrm{~mm}$ от центра взрыва - $220 \mathrm{~nm}$. Таким образом, оказалось, что чем дальше образец был изначально расположен от центра взрыва, тем бо́льшую величину имел вычисленный из кривых МУРР размер зерен (доменов). Следует отметить, что при анализе кривой МУРР от контрольного образца в соответствии с моделью Гинье была также получена величина около $220 \mathrm{~nm}$.

Применение модели Порода привело к следующим результатам. Величины показателя степени, полученные при аппроксимации КДР степенной функцией в двух противоположных направлениях относительно прямого пучка, составили по модулю: при расстоянии $150 \mathrm{~mm}$ от образца до центра взрыва (рис. 2) - 1.0 и 2.9; для расстояния $300 \mathrm{~mm}$ (рис. 3$)-1.4$ и 3.9 ; в случае $500 \mathrm{~mm}$ (рис. 4$)-1.0$ и 2.8 .

Значения степенного показателя Порода около 1 являются свидетельством того, что каждый из образцов содержит линейчатые компоненты или одномерные дефекты (такие, как дислокации и дислокационные петли). Для кристаллов, подвергнутых механическому воздействию, характерны высокие концентрации дислокаций, ведущие к формированию дислокационных стенок - групп из параллельных краевых дислокаций, лежащих в плоскости, перпендикулярной их общему вектору Бюргерса [8]. В кристаллических материалах дислокационные стенки являются распространенным типом интерфейсов между доменами и зернами [8]. Таким образом, можно предположить, что во взорванном материале домены разделены дислокационными стенками, обладающими линейчатой низкоразмерной структурой.

Кроме того, на каждой из полученных кривых МУРР наблюдались интенсивные брэгговские пики, соответствовавшие латеральному линейному размеру от 80 до $100 \mathrm{~nm}$, и последовательности брэгговских пиков, отвечающих величинам от 300 до $500 \mathrm{~nm}$. Для образца, исходно расположенного на расстоянии $150 \mathrm{~mm}$ от центра взрыва, интенсивный интерференционный рефлекс отвечает величине около $80 \mathrm{~nm}$, а серия малых брэгговских пиков - около $300 \mathrm{~nm}$. Для образца, отвечающего расстоянию $300 \mathrm{~mm}$, соответствующие линейные значения примерно равны $90 \mathrm{~nm}$ и $500 \mathrm{~nm}$, а для образца с начальным расстоянием $500 \mathrm{~mm}$ от центра взрыва $-100 \mathrm{~nm}$ и $500 \mathrm{~nm}$, как и у контрольного образца. Таким образом, все полученные линейные величины возрастали с увеличением расстояния от изначального местоположения пластины до центра взрыва. Тот факт, что полученные КДР содержат большое количество брэгговских пиков, может свидетельствовать о том, что в образцах присутствуют двух- или трехмерные сверхрешетки, образовавшиеся, вероятно, в процессе трещинообразования в объеме высокомодульного кристалла.

Важно отметить, что полученные результаты позволяют - с учетом конкретного типа используемого взрывчатого вещества - прогнозировать степень разрушения высокомодульных кристаллов в направлении увеличения зоны откола с сохранением качества кристаллов. 


\section{4. Заключение}

В результате анализа данных МУРР установлены характерные размеры зерен во взорванной модельной породе. Получена оценка периодических размеров (межплоскостных расстояний сверхрешетки) в материале, образовавшемся в результате воздействия взрыва на кварцевые пластины. Установлено присутствие низкоразмерных (преимущественно линейных) компонент в исследованных образцах модельной породы. Сформулировано предположение, что домены в образцах разделены дислокационными стенками.

\section{Список литературы}

[1] Д. Элуэлл. Искусственные драгоценные камни / Пер. с англ. Мир, М. (1986). 160 с.

[2] Ю.Л. Орлов. Минералогия алмаза. Наука, М. (1984). 172 с.

[3] F.P. Bundy. Physica A 156, 169 (1989).

[4] В.А. Боровиков, И.Ф. Ванягин. Моделирование действия взрыва при разрушении горных пород. Недра, М. (1990). $232 \mathrm{c}$.

[5] Р.Н. Кютт, Э.А. Сморгонская, С.К. Гордеев, А.В. Гречинская, А.М. Данишевский. ФТТ 41, 1484 (1999).

[6] Small-Angle X-Ray Scattering / Ed. O. Glatter, O. Kratky. Academ. Press, London (1982). 516 p.

[7] М.Е. Бойко, М.Д. Шарков, А.М. Бойко, С.Г. Конников, А.В. Бобыль, Н.С. Будкина. ЖТФ 85, 11, 1 (2015).

[8] Н. Ашкрофт, Н. Мермин. ФТТ / Пер. с англ. Мир, М. (1979). T. $2.424 \mathrm{c}$. 